\title{
Awareness of Diabetic Foot Complications in Type 2 Diabetes Population in Rural India: Are we doing enough?
}

Snehil Dixit ${ }^{*}$ and Shashi Kumar

Department of Physiotherapy, School of Allied Health Sciences (SOAHS), Manipal University, India

*Corresponding author:Snehil Dixit, Department of Physiotherapy, School of Allied Health Sciences (SOAHS), Manipal University, Manipal 576104, Karnataka, India, Email: snehildixit83@gmail.com

Rec date: Apr 05, 2014, Acc date: Apr 23, 2014, Pub date: Apr 28, 2014

Copyright: ( 2014 Dixit S, et al. This is an open-access article distributed under the terms of the Creative Commons Attribution License, which permits unrestricted use, distribution, and reproduction in any medium, provided the original author and source are credited.

Almost 246 million people worldwide are affected with Type 2 diabetes and it is expected to affect 380 million people by 2025 , representing as much as $7.1 \%$ of the global adult population [1]. World health organization (WHO) estimates $60 \%$ of the diabetic population will be from developing countries of Asia by 2025 [2]. The highest regional prevalence was reported for North America (10.2\%) followed by South Asia (6.7\%) [3].

India is home to around 50.8 million of individuals with diabetes and this number is further expected to increase to 87.0 million by 2030 [4]. A crossectional study that screened 323 individuals across India stated that $8.7 \%$ of people suffered from foot ulcer or blisters in diabetes during 1st year of onset [5]. This signifies a serious problem among Indian diabetic population regarding thier awareness about foot care.

Diabetic peripheral neuropathy is the most common complication of type 2 diabetes which starts early in type 2 diabetes. There are various risk factors contributing to diabetes globally among which rapid population growth, aging, urbanization, dyslipidaemia, insulin resistance, hypertension, and increasing prevalence of obesity and physical inactivity are the primary causative factors [6]. Potluri et al. in 2009 conducted a study on microvascular complications in individuals with diabetes and its prevalence in Indian, Mauritius and the United Kingdom population. They found neuropathy as a highly prevalent complication among Indian diabetic population [7].Moreover, the risk for stroke is 2 to 4 times higher among people with diabetes. Even experts suggest that around 10 per cent of people with diabetes will develop a foot ulcer at some point [8]. Diabetes mellitus is associated with many musculoskeletal and systemic complications where diabetic foot is a common complication with high prevalence of $52 \%$ among diabetics [9].

Diabetic foot usually starts with sensory complications like pain, numbness and paresthesia which on its due course progresses to motor changes like intrinsic muscle atrophy and muscle weakness causing structural and functional alterations which leads to abnormal plantar pressures which is a high risk factor for development of plantar pressure ulcers. Loss of protective sensation to noxious stimuli can easily result in trauma induced by microtrauma to the skin and bone or trauma caused by stepping on a sharp object or skin injury due to ill-fitting shoes [10].

Diabetic ulcers have not only added to the financial burden to the nation's economies worldwide but have also caused increased mortality and morbidity in population with diabetes. Diabetic foot ulcers have high chances of recurrence in an individual's lifetime leading to a poor quality of life in individuals suffering from diabetic foot.A diabetic foot ulcer not only causes immense psychological stress on the person but also causes decline or loss of mobility and body function. Population in rural India sleeps in huts, farm house or outdoors and due to loss of sensation in feet, the people in rural India are unaware of the bites by rodents. Moreover, frequency of wearing boots or protective footwear's is very less in rural India among farmers who are frequently required in the field. Hence rural populations being more vulnerable for chronic ulcers have higher chances of amputation of the limb causing a decline in their functional and vocational activities.

However, primary prevention methods like simple education about complications in type 2 diabetes regarding diabetic foot ulcers, postural impairments, and stroke can play a key role in the management of complications among individuals suffering from type 2 diabetes in rural India. In few studies researcher have also found that endurance training appears to be an effective method to control progression of DPN [11] hence Structured exercise program and education can form a special focus in controlling complications in diabetic foot.

There is a need to form special focus group in type 2 diabetes complications or research cell across India or a central registry that can take into account not only the number of peoples getting affected but also devise a patient friendly online or telephonic supportfor education and management of diabetic foot related problems, mobile clinics for assistance and vocational rehabilitation. This may help individual patients from coping up the ill effects of type 2 diabetes.

Moreover in future we need clinical trials focusing on primary prevention strategies and secondary management strategies of the complications, which may seek a need of inter-professional alliances to prevent functional disability and mortality in diabetic foot.

\section{References}

1. International Diabetes Foundation (2006) Diabetes: A Global Threat. Brussels, Belgium: International Diabetes Foundation: 1-15.

2. Mohan V, Mathur P, Deepa R, Deepa M, Shukla DK, et al. (2008) Urban rural differences in prevalence of self-reported diabetes in India--the WHO-ICMR Indian NCD risk factor surveillance. Diabetes Res ClinPract 80: $159-168$

3. Shaw JE, Sicree RA, Zimmet PZ (2010) Global estimates of the prevalence of diabetes for 2010 and 2030. Diabetes Res ClinPract 87: 4-14.

4. Ramachandran A, Das AK, Joshi SR, Yajnik CS, Shah S, et al. (2010) Current status of diabetes in India and need for novel therapeutic agents. JAPI 58: 7-9.

5. Dixit S, Maiya A, Khetrapal H, Agrawal B, Vidyasagar S, et al. (2011) A questionnaire based survey on awareness of diabetic foot care in Indian population with diabetes: a cross-sectional multicentre study. Indian J Med Sci 65: 411-423. 
Citation: Dixit S and Kumar S (2014) Awareness of Diabetic Foot Complications in Type 2 Diabetes Population in Rural India: Are we doing enough?. J Diabetes Metab 5: 363. doi:10.4172/2155-6156.1000363

Page 2 of 2

6. Bate KL, Jerums G (2003) 3: Preventing complications of diabetes. Med J Aust 179: 498-503.

7. Potluri R, Purmah Y, Dowlut M, Sewpaul N, Lavu D (2009) Microvascular diabetic complications are more prevalent in India compared to Mauritius and the UK due to poorer diabetic control. Diabetes Res ClinPract 86: e39-40.

8. Kothari V, Stevens RJ, Adler AI, Stratton IM, Manley SE, et al. (2002) UKPDS 60: risk of stroke in type 2 diabetes estimated by the UK Prospective Diabetes Study risk engine. Stroke 33: 1776-1781.
9. Viswanathan V, Madhavan S, Rajasekar S, Chamukuttan S, Ambady R (2006) Urban-rural differences in the prevalence of foot complications in South-Indian diabetic patients. Diabetes Care 29: 701-703.

10. Papanas N, Maltezos E (2009) The diabetic foot: a global threat and a huge challenge for Greece. Hippokratia 13: 199-204.

11. Dixit S, Maiya AG, Shastry BA (2013) Effect of aerobic exercise on peripheral nerve functions of population with diabetic peripheral neuropathy in type 2 diabetes: A single blind, parallel group randomized controlled trial. J Diabetes Complications. [doi: 10.1016/j.jdiacomp]. 